\title{
Clark Level III
}

National Cancer Institute

\section{Source}

National Cancer Institute. Clark Level III. NCI Thesaurus. Code C94814.

A morphologic finding indicating that the cutaneous melanoma has invaded the entire thickness of the papillary dermis but the malignant cellular infiltrate does not extend into the reticular dermis. 